\title{
Robotic Surgery for Rectal Cancer: An Update in 2015
}

\section{Jung Myun Kwak, MD, PhD \\ Seon Hahn Kim, MD, PhD}

Colorectal Division, Department of Surgery, Korea University Anam Hospital,

Korea University College of Medicine, Seoul, Korea

Correspondence: Seon Hahn Kim, MD, PhD Colorectal Division, Department of Surgery, Korea University Anam Hospital,

Korea University College of Medicine,

73 Inchon-ro, Seongbuk-gu, Seoul 02841, Korea

Tel: 82-2-920-6644

Fax: 82-2-928-1631

E-mail: drkimsh@korea.ac.kr

Received December 11, 2015

Accepted January 19, 2016

Published Online February 3, 2016
During the last decade, robotic surgery for rectal cancer has rapidly gained acceptance among colorectal surgeons worldwide, with well-established safety and feasibility. The lower conversion rate and better surgical specimen quality of robotic compared with laparoscopic surgery potentially improves survival. Earlier recovery of voiding and sexual function after robotic total mesorectal excision is another favorable outcome. Long-term survival data are sparse with no evidence that robotic surgery offers major benefits in oncological outcomes. Although initial reports are promising, more rigorous scientific evaluation in multicenter, randomized clinical trials should be performed to definitely determine the advantages of robotic rectal cancer surgery.

\section{Introduction}

Since a robotic surgical system was developed in the early 1990s and the first robotic-assisted radical prostatectomy (RARP) was reported in 2001 [1], robotic surgery has spread in many surgical specialties, changing surgical management. In the United States, RARP has increased steeply from $8 \%$ of radical prostatectomies in 2004 to $67 \%$ in 2010 [2]. Likewise, the number and indications for robotic gynecological surgery

\author{
Key words \\ Rectal neoplasms, Robotics, Laparoscopy, \\ Total mesorectal excision
}


robotic surgery appears to offer great benefits for total mesorectal excision (TME) for rectal cancer. For example, abdominal cavity procedures such as right hemicolectomy and high anterior resection are relatively uncomplicated and can be performed easily by laparoscopic surgery. According to a recent study that analyzed nationwide data on current surgical management for colorectal cancer surgery in Korea, robotic surgery was used for 185 cases of rectal cancer in 2008, increasing steadily to 490 cases in 2013. In contrast, robotic colon cancer surgery decreased from 110 cases in 2009 to only 10 cases in 2013 [9]. Furthermore, robotic colorectal surgery is more expensive than conventional laparoscopy.

Most relevant recent reports have focused on the clinical benefits of robotic rectal cancer surgery compared with laparoscopic surgery [10-27]. The indications for robotic and laparoscopic rectal cancer surgery are not different. No contraindications apply solely to robotic surgery for rectal cancer. However, no clear advantage supporting the use of this expensive technology has been demonstrated. For robotic rectal cancer surgery to become the preferred minimally invasive option, it must demonstrate that it does not have the technical difficulties and steep learning curve of laparoscopic surgery. Therefore, we reviewed current evidence to compare surgical, pathological, functional, and oncological outcomes of robotic and laparoscopic surgery for rectal cancer.

\section{Materials and Methods}

We searched the MEDLINE database with PubMed for all articles published between 2002 and 2015 using the keywords "robot"," "da Vinci," "colo"," and "*rectal." We also manually searched articles using references from related articles. The final search was performed in November 2015. Only papers published in English were included; studies with only abstracts and meeting reports were excluded. Articles were chosen for their relationship to the topic. When multiple studies used the same patient population, the most recent publication was used.

\section{Short-Term Surgical Outcomes of Safety and Feasibility}

Robotic surgery for rectal cancer has been established as safe and feasible. Short-term surgical outcomes of robotic surgery for rectal cancer were reviewed and compared with laparoscopic or open rectal cancer surgery; results are in Table 1.

Initially, a longer operating time was generally accepted to be a drawback of robotic rectal cancer surgery compared with laparoscopic procedures. However, recent studies report equivalent or even shorter operating times for robotic surgery for rectal cancer $[10,13,16,21]$. As most studies were published by highly experienced laparoscopic colorectal surgeons, the main reason underlying the initially reported lengthy operating times for robotic surgery was likely a difference in the level of mastery for the two operative techniques. Operating time does not appear to be an issue after surgeons accumulate experience and overcome the learning curve.

An excellent conversion rate is consistently reported in initial studies of robotic surgery. Because converted patients have higher complication rates and worse oncological outcomes, the low conversion rate for robotic rectal cancer surgery suggests expected better postoperative courses and improved oncological outcomes [28-31]. Postoperative recovery appears to be similar for robotic and laparoscopic surgery. Postoperative complication rates are also similar for these two procedures.

\section{Pathological and Oncological Outcomes}

Pathological outcomes for several prognostic indicators for robotic and laparoscopic surgery groups are in Table 2 [10-27]. It is well established that increasing the number of retrieved lymph nodes has a strong impact on prognosis [32]. Circumferential resection margin (CRM) involvement in surgical specimens is a well-known prognostic factor for local recurrence [33,34]. The length of the distal resection margin and TME completeness are thought to reflect surgical quality and affect long-term oncological outcomes.

Most studies did not find significant differences between robotic and laparoscopic rectal cancer surgery in number of retrieved lymph nodes. Based on recommendations from the College of American Pathologists about the minimum number of nodes to be dissected, the reported mean and median numbers of retrieved lymph nodes are acceptable [35]. The length of distal resection margins was not significantly different for robotic, laparoscopic (or open) surgery for patients who underwent rectal cancer surgery. The rate of CRM involvement was also not different between the two groups in all except one series [21].

Macroassessment and microassessment of surgical specimens quality are made by pathologists to determine TME 
突

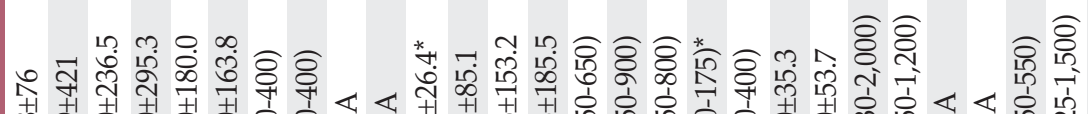

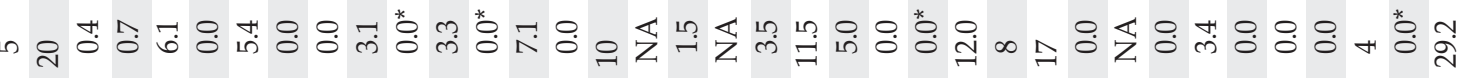

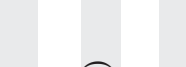




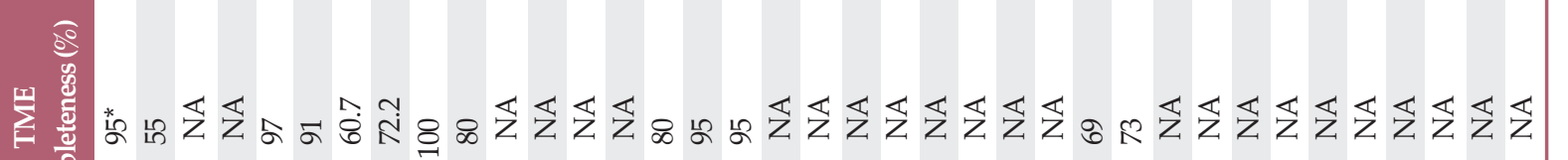

$\frac{0}{\frac{9}{8}}$

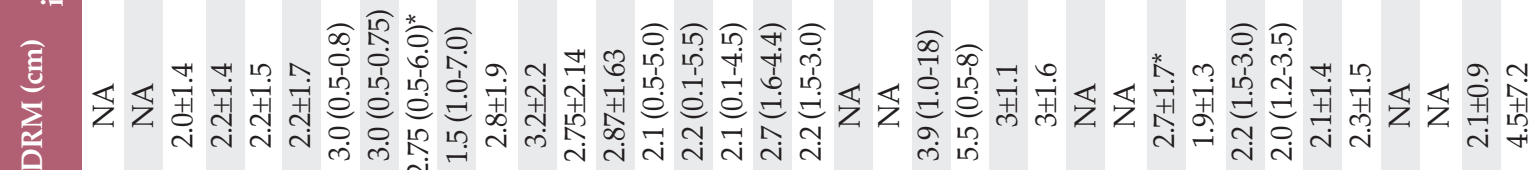

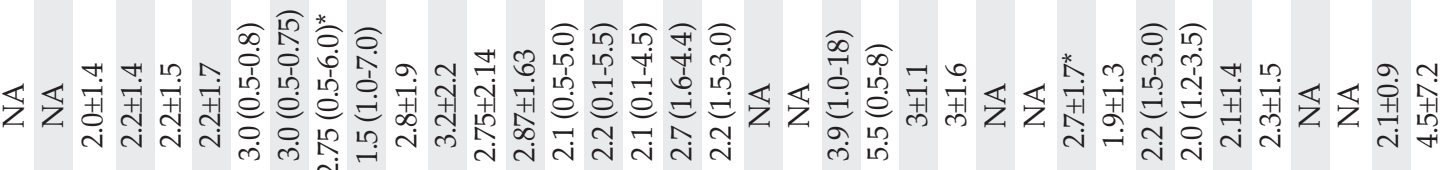

登

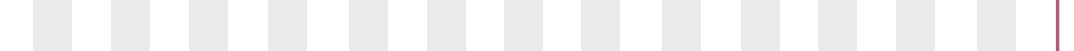

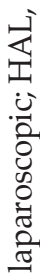

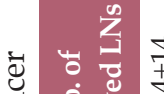

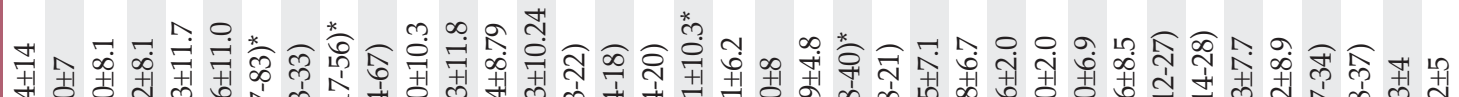

เกี

胥

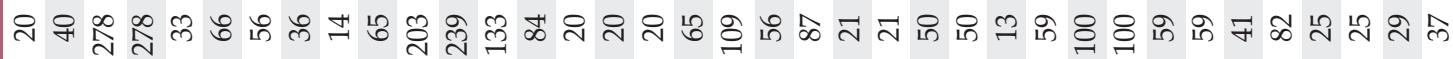

常

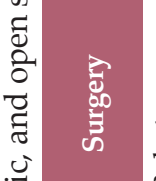

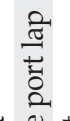

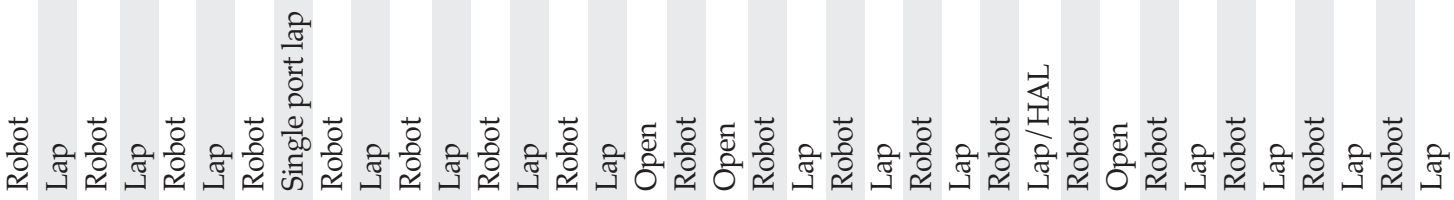
은

啇
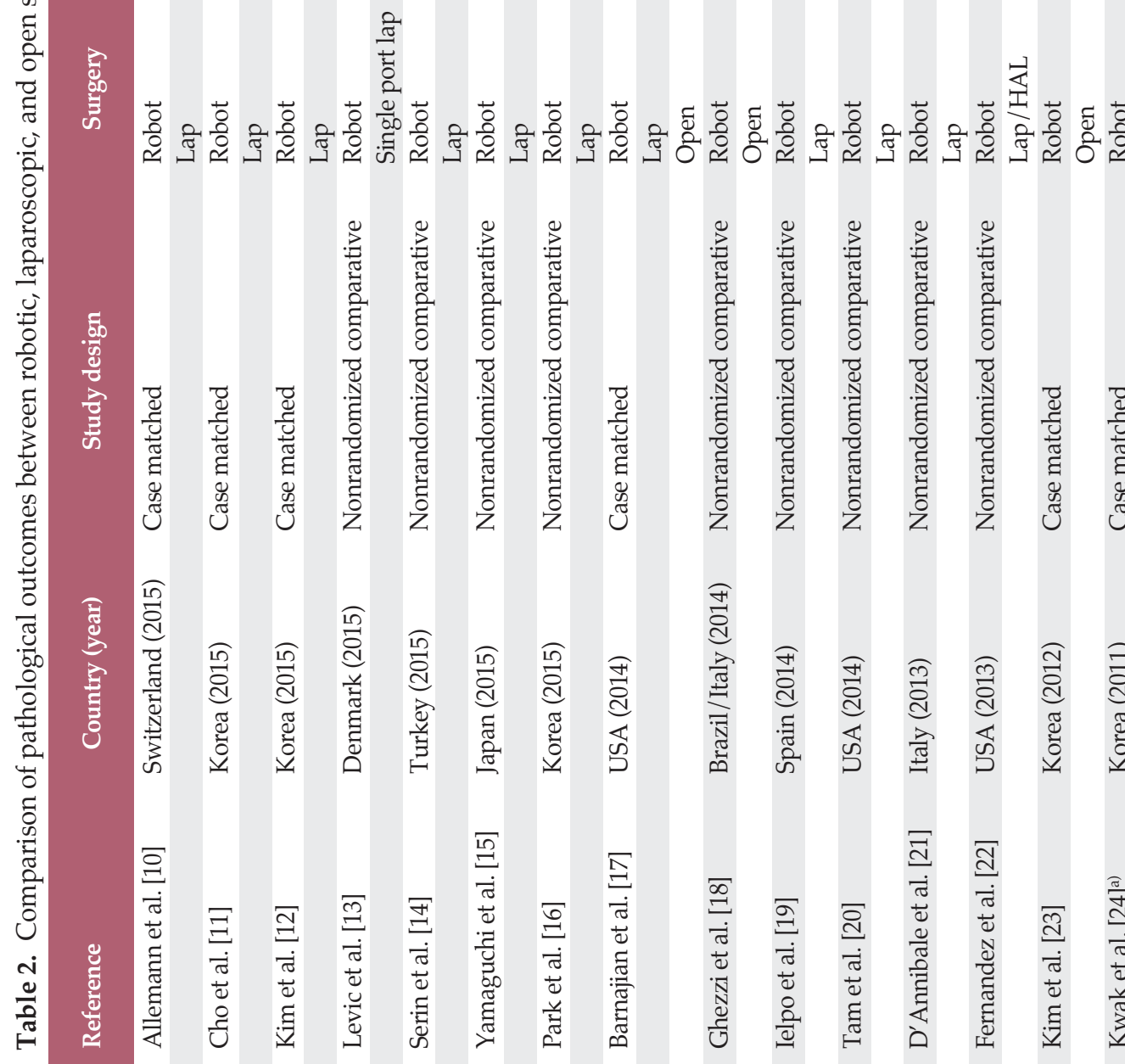

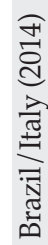

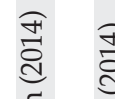

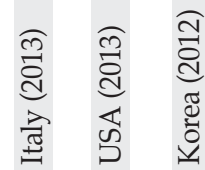

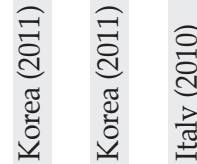

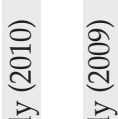

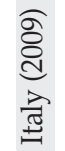

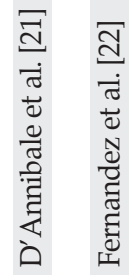

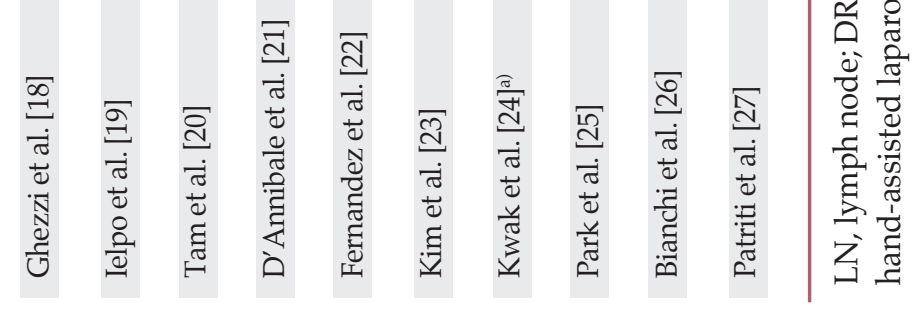




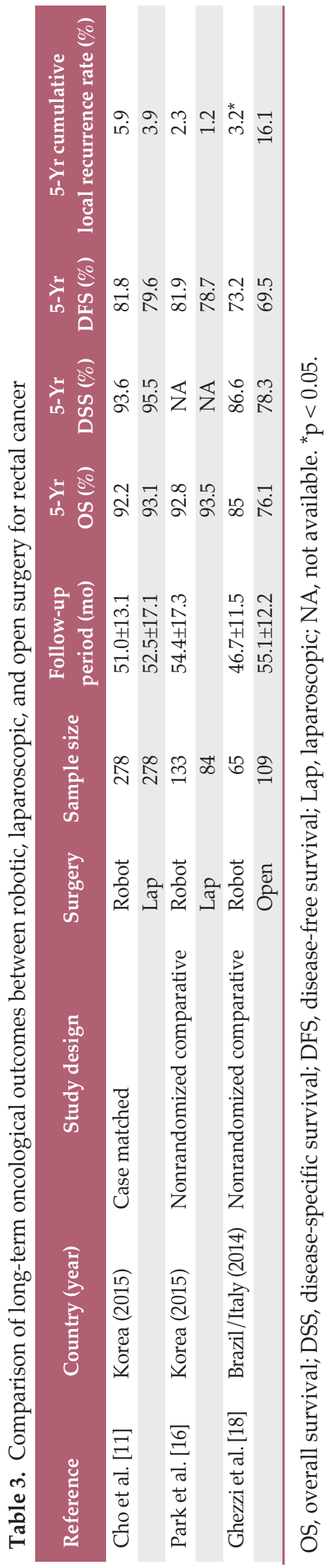

completeness, another predictor of local recurrence [36]. Baik et al. [37] indicated that the macroscopic completeness of TME for surgical specimens represents TME quality more precisely than CRM involvement, because CRM involvement is influenced by surgical quality and location, size and progression of the tumor and metastatic lymph nodes. Baik et al. [37] reported that macroscopic TME grading of specimens was significantly better in a robotic surgery group $(92.9 \%$ for robotic vs. $75.4 \%$ for laparoscopic surgery, $\mathrm{p}=0.033$ ). Allemann et al. [10] also reported significantly better TME quality in a robotic than a laparoscopic group (complete TME: 95\% vs. $55 \%, \mathrm{p}=0.0003)$ and a trend for a lower rate of CRM involvement in the robotic group ( $10 \%$ vs. $25 \%, \mathrm{p}=0.1)$. However, other studies failed to demonstrate the superiority of robotic over laparoscopic surgery for TME quality or reported quantitatively poorer TME quality for robotic than laparoscopic surgery [12-14,17]. Because demonstrating the clinical benefits of robotic surgery for rectal cancer is difficult, some studies have evaluated TME quality as the primary endpoint. However, no evidence indicates that better TME quality translates into better survival from robotic rectal cancer surgery $[10,16,37]$.

Long-term survival data are sparse (Table 3). Cho et al. [11] performed case-matched analyses of long-term oncological outcomes for fully robotic and laparoscopic TME patients, excluding hybrid robotic surgery. No significant differences were found between the two groups for 5-year overall, or disease-specific, disease-free, or local recurrence-free survival. Another study from the same institution by Park et al. [16] compared 133 hybrid-robotic surgeries and 84 laparoscopic low-anterior resections for rectal cancer by a single surgeon. The mean follow-up period was 54.4 months. The 5 -year overall survival and disease-free survival rates were not different between the two groups. Cumulative incidence of local recurrence was excellent in both groups: $2.3 \%$ in the robotic group and $1.2 \%$ in the laparoscopic group ( $\mathrm{p}=0.649$ ). Ghezzi et al. [18] compared survival in robotic and open rectal cancer surgery groups. Mean follow-up was 46.7 and 55.1 months, respectively. Five-year overall, disease-specific, and disease-free survival rates were not different between the robot and open groups; however, the 5-year cumulative local recurrence rate was significantly lower in the robot group ( $3.2 \%$ vs. $16.1 \%, \mathrm{p}=0.024)$.

At present, no evidence supports that robotic surgery offers major benefits in surgical or oncological outcomes. Currently, several randomized controlled trials are underway to address whether robotic surgery has more favorable surgical and oncological outcomes compared with laparoscopic surgery. However, oncological outcomes should be equal, regardless of surgical approach, with strict adherence to surgical principles. For prostate cancer, multiple RARP series have demonstrated the safety, efficiency, and repro- 
ducibility of the procedure, although it does not have superior oncological outcomes compared to laparoscopic or open surgery [38-40]. Despite the higher medical cost and lack of advantages, a growing number of radical prostatectomies are performed with robotic assistance. We anticipate an increase in rectal cancers treated with robotic surgery without waiting for clear demonstration of its oncological benefits.

\section{Functional Outcomes}

Voiding and sexual dysfunctions after rectal cancer surgery are common and well-known sequelae. The incidences of postoperative urinary and sexual dysfunction have decreased notably since the introduction of TME and autonomic nerve preservation techniques. Nonetheless, these adverse events remain a serious problem, with $4 \%-10 \%$ of TME patients reporting urinary dysfunction and 5\%-30\% reporting sexual dysfunction [41-44]. Regardless of the advantages of a laparoscopic approach such as magnified view and direct visualization of the low pelvis, the technical difficulties associated with laparoscopic surgery increase the risk of inadvertent damage to autonomic nerves. In the MRC CLASICC trial, laparoscopic rectal resection did not cause voiding dysfunction but tended to adversely affect male sexual function. Particularly, TME and conversion to open surgery were identified as independent risk factors for worse male sexual function [45].

Robotic TME is hypothesized to achieve better preservation of urinary and sexual functions than laparoscopic TME. Technological advantages in robotic surgical systems, including advanced three-dimensional views, finer dissection using the freely articulating EndoWrist, and stable traction with a third robotic arm are expected to result in greater preservation of autonomic nerves than with laparoscopic surgery. The low conversion rate of robotic TME compared to laparoscopic TME supports this hypothesis and currently available evidence is promising. Kim et al. [46] compared voiding and sexual function before and after robotic or laparoscopic TME for rectal cancer. The study demonstrated that voiding and sexual function recovered earlier in a robotic TME group than a laparoscopic group [46]. Park et al. [47] compared functional outcomes of robotic and laparoscopic intersphincteric resection for low rectal cancer, and reported a trend toward earlier recovery of male sexual function in the robotic than the laparoscopic group. A report by D'Annibale et al. [21] demonstrated that erectile function was preserved in all sexually active patients who underwent robotic TME. However, function was preserved only in $43 \%$ of patients who underwent laparoscopic TME and this difference was statistically significant $(\mathrm{p}=0.045)$ [21]. These results should be interpreted with caution because of the relatively small number of patients enrolled in the three studies. Publication bias is another consideration.

\section{Technical Evolution and Future Perspectives}

Recently developed robotic instruments and new robotic platform technologies require further investigation. An example is the robotic stapler (da Vinci EndoWrist Stapler $45)$, which we have used in our recent rectal surgery practice. This stapler is fully controlled from a surgeon's console, provides a full cone of articulation, and features SmartClamp feedback. Software detects adequate closure of the stapler jaws on the target tissue based on tissue thickness. We are interested in determining whether use of this instrument results in better clinical outcomes, particularly for anastomotic leakage.

FireFly fluorescence imaging with current surgical robotic systems provides integrated fluorescence images using nearinfrared technology. The images allow surgeons to distinguish cancerous from normal tissue and evaluate organ and tissue perfusion. Although indications for fluorescence imaging are limited to assessment of anastomotic perfusion in colorectal surgery, future technological advances and development of new fluorescent agents will expand its clinical applications [48-50].

Undoubtedly, future robotic systems will have little resemblance to the machines that are in use today. The extent to which current robotic surgical systems will undergo evolutionary changes over the next decades is unclear. Many research and development groups are working to develop robotic technologies. The development of artificial intelligence [51,52], miniaturization of surgical robots [53,54], incorporation of nanotechnology [51], and development of telepresence surgery with improved communication systems are all likely to impact robotic surgery in the near future.

\section{Conclusion}

Although robotic rectal cancer surgery is expensive, its safety and feasibility are well established. Its lower conversion rate and better surgical specimen quality compared to laparoscopic surgery may potentially improve survival. Although initial reports are promising, randomized clinical trials should be performed to definitely determine the safety, 
efficacy, and long-term oncological and functional benefits of robotic rectal cancer surgery.

As the technology for surgical robots continues to advance rapidly, future robotic systems will become increasingly affordable and more refined. Adoption of new technology occurs over time, and technological advantages will ensure that robotic surgical systems are eventually part of the normal armamentarium for routine surgical tasks.

\section{Conflicts of Interest}

Conflict of interest relevant to this article was not reported.

\section{References}

1. Binder J, Kramer W. Robotically-assisted laparoscopic radical prostatectomy. BJU Int. 2001;87:408-10.

2. Lowrance WT, Eastham JA, Savage C, Maschino AC, Laudone VP, Dechet $C B$, et al. Contemporary open and robotic radical prostatectomy practice patterns among urologists in the United States. J Urol. 2012;187:2087-92.

3. Holloway RW, Patel SD, Ahmad S. Robotic surgery in gynecology. Scand J Surg. 2009;98:96-109.

4. Weber PA, Merola S, Wasielewski A, Ballantyne GH. Telerobotic-assisted laparoscopic right and sigmoid colectomies for benign disease. Dis Colon Rectum. 2002;45:1689-94.

5. Delaney CP, Lynch AC, Senagore AJ, Fazio VW. Comparison of robotically performed and traditional laparoscopic colorectal surgery. Dis Colon Rectum. 2003;46:1633-9.

6. Rawlings AL, Woodland JH, Vegunta RK, Crawford DL. Robotic versus laparoscopic colectomy. Surg Endosc. 2007; 21:1701-8.

7. deSouza AL, Prasad LM, Park JJ, Marecik SJ, Blumetti J, Abcarian H. Robotic assistance in right hemicolectomy: is there a role? Dis Colon Rectum. 2010;53:1000-6.

8. D'Annibale A, Morpurgo E, Fiscon V, Trevisan P, Sovernigo G, Orsini C, et al. Robotic and laparoscopic surgery for treatment of colorectal diseases. Dis Colon Rectum. 2004;47: 2162-8.

9. Park SJ, Lee KY, Lee SH. Laparoscopic surgery for colorectal cancer in Korea: nationwide data from 2008 2013. J Minim Invasive Surg. 2015;18:39-43.

10. Allemann P, Duvoisin C, Di Mare L, Hubner M, Demartines N, Hahnloser D. Robotic-assisted surgery improves the quality of total mesorectal excision for rectal cancer compared to laparoscopy: results of a case-controlled analysis. World J Surg. 2016;40:1010-6.

11. Cho MS, Baek SJ, Hur H, Min BS, Baik SH, Lee KY, et al. Short and long-term outcomes of robotic versus laparoscopic total mesorectal excision for rectal cancer: a case-matched retrospective study. Medicine (Baltimore). 2015;94:e522.

12. Kim YS, Kim MJ, Park SC, Sohn DK, Kim DY, Chang HJ, et al. Robotic versus laparoscopic surgery for rectal cancer after preoperative chemoradiotherapy: case-matched study of shortterm outcomes. Cancer Res Treat. 2016;48:225-31.

13. Levic K, Donatsky AM, Bulut O, Rosenberg J. A comparative study of single-port laparoscopic surgery versus roboticassisted laparoscopic surgery for rectal cancer. Surg Innov. 2015;22:368-75.

14. Serin KR, Gultekin FA, Batman B, Ay S, Kapran Y, Saglam S, et al. Robotic versus laparoscopic surgery for mid or low rectal cancer in male patients after neoadjuvant chemoradiation therapy: comparison of short-term outcomes. J Robot Surg. 2015;9:187-94

15. Yamaguchi T, Kinugasa Y, Shiomi A, Tomioka H, Kagawa $H$, Yamakawa Y. Robotic-assisted vs. conventional laparoscopic surgery for rectal cancer: short-term outcomes at a single center. Surg Today. 2015 Oct 19 [Epub]. http://dx.doi.org/10. 1007 / s00595-015-1266-4.

16. Park EJ, Cho MS, Baek SJ, Hur H, Min BS, Baik SH, et al. Longterm oncologic outcomes of robotic low anterior resection for rectal cancer: a comparative study with laparoscopic surgery. Ann Surg. 2015;261:129-37.

17. Barnajian M, Pettet D 3rd, Kazi E, Foppa C, Bergamaschi R. Quality of total mesorectal excision and depth of circumferential resection margin in rectal cancer: a matched comparison of the first 20 robotic cases. Colorectal Dis. 2014;16:603-9.

18. Ghezzi TL, Luca F, Valvo M, Corleta OC, Zuccaro M, Cenciarelli $S$, et al. Robotic versus open total mesorectal excision for rectal cancer: comparative study of short and long-term outcomes. Eur J Surg Oncol. 2014;40:1072-9.

19. Ielpo B, Caruso R, Quijano Y, Duran H, Diaz E, Fabra I, et al. Robotic versus laparoscopic rectal resection: is there any real difference? A comparative single center study. Int J Med Robot. 2014;10:300-5.

20. Tam MS, Abbass M, Abbas MA. Robotic-laparoscopic rectal cancer excision versus traditional laparoscopy. JSLS. 2014;18: e2014.00020.

21. D'Annibale A, Pernazza G, Monsellato I, Pende V, Lucandri G, Mazzocchi P, et al. Total mesorectal excision: a comparison of oncological and functional outcomes between robotic and laparoscopic surgery for rectal cancer. Surg Endosc. 2013; 27:1887-95.

22. Fernandez R, Anaya DA, Li LT, Orcutt ST, Balentine CJ, Awad SA, et al. Laparoscopic versus robotic rectal resection for rectal cancer in a veteran population. Am J Surg. 2013;206:509-17.

23. Kim JC, Yang SS, Jang TY, Kwak JY, Yun MJ, Lim SB. Open 
versus robot-assisted sphincter-saving operations in rectal cancer patients: techniques and comparison of outcomes between groups of 100 matched patients. Int J Med Robot. 2012;8:468-75.

24. Kwak JM, Kim SH, Kim J, Son DN, Baek SJ, Cho JS. Robotic vs laparoscopic resection of rectal cancer: short-term outcomes of a case-control study. Dis Colon Rectum. 2011;54:151-6.

25. Park JS, Choi GS, Lim KH, Jang YS, Jun SH. Robotic-assisted versus laparoscopic surgery for low rectal cancer: casematched analysis of short-term outcomes. Ann Surg Oncol. 2010;17:3195-202.

26. Bianchi PP, Ceriani C, Locatelli A, Spinoglio G, Zampino MG, Sonzogni A, et al. Robotic versus laparoscopic total mesorectal excision for rectal cancer: a comparative analysis of oncological safety and short-term outcomes. Surg Endosc. 2010;24: 2888-94.

27. Patriti A, Ceccarelli G, Bartoli A, Spaziani A, Biancafarina A, Casciola L. Short- and medium-term outcome of robot-assisted and traditional laparoscopic rectal resection. JSLS. 2009;13: 176-83.

28. Delgado S, Momblan D, Salvador L, Bravo R, Castells A, Ibarzabal A, et al. Laparoscopic-assisted approach in rectal cancer patients: lessons learned from >200 patients. Surg Endosc. 2004;18:1457-62.

29. Dulucq JL, Wintringer P, Stabilini C, Mahajna A. Laparoscopic rectal resection with anal sphincter preservation for rectal cancer: long-term outcome. Surg Endosc. 2005;19:1468-74.

30. Guillou PJ, Quirke P, Thorpe H, Walker J, Jayne DG, Smith $\mathrm{AM}$, et al. Short-term endpoints of conventional versus laparoscopic-assisted surgery in patients with colorectal cancer (MRC CLASICC trial): multicentre, randomised controlled trial. Lancet. 2005;365:1718-26.

31. Rottoli M, Bona S, Rosati R, Elmore U, Bianchi PP, Spinelli A, et al. Laparoscopic rectal resection for cancer: effects of conversion on short-term outcome and survival. Ann Surg Oncol. 2009;16:1279-86.

32. Resch A, Langner C. Lymph node staging in colorectal cancer: old controversies and recent advances. World J Gastroenterol. 2013;19:8515-26.

33. Quirke P, Durdey P, Dixon MF, Williams NS. Local recurrence of rectal adenocarcinoma due to inadequate surgical resection: histopathological study of lateral tumour spread and surgical excision. Lancet. 1986;2:996-9.

34. Wibe A, Rendedal PR, Svensson E, Norstein J, Eide TJ, Myrvold HE, et al. Prognostic significance of the circumferential resection margin following total mesorectal excision for rectal cancer. Br J Surg. 2002;89:327-34.

35. Compton CC, Fielding LP, Burgart LJ, Conley B, Cooper HS, Hamilton SR, et al. Prognostic factors in colorectal cancer. College of American Pathologists Consensus Statement 1999. Arch Pathol Lab Med. 2000;124:979-94.

36. Nagtegaal ID, van de Velde CJ, van der Worp E, Kapiteijn E, Quirke P, van Krieken JH, et al. Macroscopic evaluation of rectal cancer resection specimen: clinical significance of the pathologist in quality control. J Clin Oncol. 2002;20:1729-34.

37. Baik SH, Kwon HY, Kim JS, Hur H, Sohn SK, Cho CH, et al.
Robotic versus laparoscopic low anterior resection of rectal cancer: short-term outcome of a prospective comparative study. Ann Surg Oncol. 2009;16:1480-7.

38. Ficarra V, Novara G, Artibani W, Cestari A, Galfano A, Graefen $\mathrm{M}$, et al. Retropubic, laparoscopic, and robot-assisted radical prostatectomy: a systematic review and cumulative analysis of comparative studies. Eur Urol. 2009;55:1037-63.

39. Novara G, Ficarra V, Mocellin S, Ahlering TE, Carroll PR, Graefen $M$, et al. Systematic review and meta-analysis of studies reporting oncologic outcome after robot-assisted radical prostatectomy. Eur Urol. 2012;62:382-404.

40. Coelho RF, Rocco B, Patel MB, Orvieto MA, Chauhan S, Ficarra V, et al. Retropubic, laparoscopic, and robot-assisted radical prostatectomy: a critical review of outcomes reported by high-volume centers. J Endourol. 2010;24:2003-15.

41. Akasu T, Sugihara K, Moriya Y. Male urinary and sexual functions after mesorectal excision alone or in combination with extended lateral pelvic lymph node dissection for rectal cancer. Ann Surg Oncol. 2009;16:2779-86.

42. Kyo K, Sameshima S, Takahashi M, Furugori T, Sawada T. Impact of autonomic nerve preservation and lateral node dissection on male urogenital function after total mesorectal excision for lower rectal cancer. World J Surg. 2006;30:1014-9.

43. Sterk P, Shekarriz B, Gunter S, Nolde J, Keller R, Bruch HP, et al. Voiding and sexual dysfunction after deep rectal resection and total mesorectal excision: prospective study on 52 patients. Int J Colorectal Dis. 2005;20:423-7.

44. Kneist W, Junginger T. Male urogenital function after confirmed nerve-sparing total mesorectal excision with dissection in front of Denonvilliers' fascia. World J Surg. 2007;31:1321-8.

45. Jayne DG, Brown JM, Thorpe H, Walker J, Quirke P, Guillou PJ. Bladder and sexual function following resection for rectal cancer in a randomized clinical trial of laparoscopic versus open technique. Br J Surg. 2005;92:1124-32.

46. Kim JY, Kim NK, Lee KY, Hur H, Min BS, Kim JH. A comparative study of voiding and sexual function after total mesorectal excision with autonomic nerve preservation for rectal cancer: laparoscopic versus robotic surgery. Ann Surg Oncol. 2012;19:2485-93.

47. Park SY, Choi GS, Park JS, Kim HJ, Ryuk JP. Short-term clinical outcome of robot-assisted intersphincteric resection for low rectal cancer: a retrospective comparison with conventional laparoscopy. Surg Endosc. 2013;27:48-55.

48. Daskalaki D, Aguilera F, Patton K, Giulianotti PC. Fluorescence in robotic surgery. J Surg Oncol. 2015;112:250-6.

49. Jafari MD, Lee KH, Halabi WJ, Mills SD, Carmichael JC, Stamos MJ, et al. The use of indocyanine green fluorescence to assess anastomotic perfusion during robotic assisted laparoscopic rectal surgery. Surg Endosc. 2013;27:3003-8.

50. Bae SU, Min BS, Kim NK. Robotic low ligation of the inferior mesenteric artery for rectal cancer using the firefly technique. Yonsei Med J. 2015;56:1028-35.

51. Chauhan S, Coelho RF, Kalan S, Satava RM, Patel VR. Evolution of robotic surgery: past, present, and future. In: Patel VR, editor. Robotic urologic surgery. 2nd ed. London: SpringerVerlag; 2012. p. 3-10. 
52. Camarillo DB, Krummel TM, Salisbury JK Jr. Robotic technology in surgery: past, present, and future. Am J Surg. 2004;188 (4A Suppl):2S-15S.

53. Rentschler ME, Dumpert J, Platt SR, Farritor SM, Oleynikov D. Natural orifice surgery with an endoluminal mobile robot.
Surg Endosc. 2007;21:1212-5.

54. Tiwari MM, Reynoso JF, Lehman AC, Tsang AW, Farritor SM, Oleynikov D. In vivo miniature robots for natural orifice surgery: State of the art and future perspectives. World J Gastrointest Surg. 2010;2:217-23. 